\title{
Determination of Sugar Profile in Viburnum Fruits and its Dosage Forms by HPLC-RID
}

\author{
Bokov DO ${ }^{1,2, *}$, Sergunova EV ${ }^{1}$, Marakhova Al ${ }^{3}$, Morokhina SL ${ }^{4}$, Plakhotnaia ON ${ }^{1}$, Krasnyuk II' (junior), Bessonov \\ $\mathbf{V V}^{2}$
}

Bokov DO ${ }^{1,2, *}$, Sergunova EV ${ }^{1}$, Marakhova $\mathrm{Al}^{3}$, Morokhina $\mathrm{SL}^{4}$, Plakhotnaia ON ${ }^{1}$, Krasnyuk II ${ }^{1}$ (junior), Bessonov VV²

${ }^{1}$ Institute of Pharmacy, Sechenov First Moscow State Medical University, 8 Trubetskaya St., bldg. 2, Moscow, 119991, RUSSIAN FEDERATION.

${ }^{2}$ Laboratory of Food Chemistry, Federal Research Center for Nutrition, Biotechnology and Food Safety, 2/14 Ustyinsky pr., Moscow, 109240, RUSSIAN FEDERATION.

${ }^{3}$ Institute of Biochemical Technology and Nanotechnology, Peoples' Friendship University of Russia (RUDN University), 6 , Miklukho-Maklaya Street, Moscow, 117198, RUSSIAN FEDERATION.

${ }^{4}$ Preparatory faculty, Financial University under the Government of the Russian Federation (Financial University), 55, Leningradsky Prospekt, Moscow, 125057, RUSSIAN FEDERATION.

\section{Correspondence}

\section{Bokov DO}

Institute of Pharmacy, Sechenov First Moscow State Medical University, 8 Trubetskaya St., bldg. 2, Moscow, 119991 RUSSIAN FEDERATION.

Laboratory of Food Chemistry, Federal Research Center for Nutrition, Biotechnology and Food Safety, 2/14 Ustyinsky pr., Moscow, 109240, RUSSIAN FEDERATION

E-mail: fmmsu@mail.ru

History

- Submission Date: 22-08-2019

- Review completed: 09-10-2019;

- Accepted Date: 11-10-2019.

DOI : 10.5530/pj.2020.12.16

Article Available online http://www.phcogj.com/v12/i1

\section{Copyright}

(C) 2020 Phcogi.Com. This is an openaccess article distributed under the terms of the Creative Commons Attribution 4.0 International license.

\section{ABSTRACT}

Background: In the Russian Federation, the viburnum fruits are used to obtain infusions and syrups as medications. This medicinal herbal raw material contains a large number of biologically active substances: vitamins, anthocyanins, proanthocyanidins, flavonoids, hydroxycinnamic acids, iridoids, carbohydrates, organic acids, lipids etc. The research aimed to study one of the biologically active substances group responsible for the formation of the organoleptic properties of aqueous extracts - monomeric carbohydrate composition and content. Materials and methods: Dried viburnum (guelder-rose) fruits, an aqueous infusion based on it, and viburnum syrup of industrial manufacture (Russia) were purchased from the pharmacy and prepared for research. For HPLC analysis of monomeric sugars Agilent 1260 Series HPLC system equipped with autosampler/injector, four-channel gradient pump, column thermostat, refractive index detector), software (ChemStation Version B.01), column (Waters Sugar-Pack I, $10 \mu \mathrm{m}, 300 \times 6.5 \mathrm{~mm}$ ) were used. Isocratic elution was performed using purified water (with the addition of Ca-EDTA $0.05 \mathrm{mg} / \mathrm{ml}$ ) as the mobile phase, at a flow rate of 0.5 $\mathrm{mL} / \mathrm{min}$. The column was maintained at $80{ }^{\circ} \mathrm{C}$, the refractive index detector - at $35{ }^{\circ} \mathrm{C}$. The injection volume was $10 \mu \mathrm{L}$, analysis time $-20 \mathrm{~min}$. Results: The main free carbohydrates of viburnum fruits and preparations based on them are glucose, fructose, and sucrose. The total content of simple sugars in the viburnum fruits is $28.393 \pm 0.528 \%$, in the infusion $0.499 \pm 0.015 \%$, in the syrup $-69.736 \pm 1.551 \%$. The characteristic ratio of glucose: fructose: sucrose in dried viburnum fruits is $8.1: 5.4: 1$, in infusion - 7.0:5.7:1, and in syrup - 9.2:8.8:1. The sugars' degree of passing into infusion is $74.34 \%$. Conclusion: The composition and content of carbohydrates determined by HPLC-RID are an important characteristic data. It can be used for viburnum fruits Russian pharmacopoeial standardization along with the quantifying total content of organic acids.

Key words: Monomeric carbohydrates, HPLC-RID, Viburnum fruits, Guelder-rose.

\section{INTRODUCTION}

In Russia, the fruits of guelder-rose (Viburnum opulus L.) and Sargent's guelder-rose (Viburnum sargentii Koehne) of honeysuckle (Caprifoliaceae Juss.) family are approved for medical use (Figure 1). State Pharmacopoeia of the USSR (XI edition, Issue 2) contains a pharmacopoeial monograph for the guelder-rose dried fruits'; the Russian State Pharmacopoeia (XIV edition, Volume IV) - for the fresh fruits of guelder-rose and Sargent's guelder-rose. "Viburnum fruits" for the infusion preparation and "Viburnum syrup" are medicines based on medicinal herbal raw materials. ${ }^{3,4}$ Viburnum fruits and products based on it are included in the Russian Register of Products. These substances have passed state registration as raw materials for biologically active additives, food, herbal teas, alcoholic and nonalcoholic balms preparation.

Viburnum fruits contain a large variety of biologically active substances (BAS $)^{5-10}$ : anthocyanins, proanthocyanidins ${ }^{11-13}$, flavonoids, hydroxycinnamic acids, iridoids, polysaccharides, organic acids ${ }^{14,15}$, lipids ${ }^{16}$, aromatic components. ${ }^{17}$
The raw material contains a unique vitamin complex: ascorbic, nicotinic acid, vitamin $\mathrm{A}$, vitamin $\mathrm{K}$, folic acid, tocopherol; micro- and macro- elements: molybdenum, magnesium, selenium, copper, manganese, zinc, iron, chromium, potassium, cobalt, calcium. ${ }^{18}$ Anti-inflammatory, antispasmodic, hypotensive, antibacterial, K-vitamin, C-vitamin, diuretic, antiradical and other types of pharmacological activity have been established for the viburnum fruits. ${ }^{3}$

Syrups are one of the dosage forms that have become widespread. Syrup - a liquid dosage form for internal use; it is a concentrated, thick aqueous solution of various sugars with medicinal substances, extracts, tinctures, fruit juices or without them. Sugar syrup (64\% sucrose solution) is used as a consistent additive and flavoring for the preparation of syrups. ${ }^{19}$ It increases osmotic pressure and completely inhibits the growth and development of microflora in the dosage form. Invert syrup, a mixture of an equal amount of glucose and fructose, is obtained from sugar syrup by inverting (hydrolyzing) sucrose by heating the sugar syrup in the presence of acid (catalyst). Viburnum syrup (Viburni sirupus) has a tonic, diaphoretic and a light diuretic effect.

Cite this article: Bokov DO, Sergunova EV, Marakhova Al, Morokhina SL, Plakhotnaia ON Krasnyuk II, et al. Determination of Sugar Profile in Viburnum Fruits and its Dosage Forms by HPLC-RID. Pharmacog J. 2020;12(1):103-8. 
Viburnum syrup is used in the complex treatment of colds, during the recovery period after diseases.

Current requirements for the standardization of medicinal plant raw materials (MPRM) include indicators characterizing the composition of BAS. The BAS quantitative determination is carried out by acid-base titration according to the pharmacopoeial monograph "Viburnum fruits". It regulates organic acids content in terms of malic acid that should be not less than $6 \%$ in fresh viburnum fruits. Carbohydrate composition and content is also an important indicator since sugars also contribute to the organoleptic properties of drugs together with organic acids.

This study aims to determine the profile and content of carbohydrates in viburnum fruits and drugs based on it.

\section{MATERIALS AND METHODS}

Viburnum fruits ("Kamelia-LT' LLC, Technic Specifications 9197-00381930399-09) are round, flattened on both sides, wrinkled, shiny fruitdrupe with a diameter of $8-12 \mathrm{~mm}$ (Figure 2.1 ). It has a barely visible column and sepals, a deepening at the place of stalk separation. In the pulp is one hard separable flat heart-shaped pit (seed). The color of the fruit is dark red or orange-red; the seed color is light brown. The smell of raw materials is weak, the taste is bitter-sour.
Viburnum infusion is a clear liquid of golden color with a pink tint, has a slight smell, a bitter-sour taste (Figure 2.2).

Viburnum syrup (registration number: N003534/01, manufacturer of ZAO "VIFITEH") is a thick liquid from orange-red to dark red color with a characteristic odor; a slight gelatinous precipitate may be observed, which dissolves when heated up to $40{ }^{\circ} \mathrm{C}$ (Figure 2.3). The smell of syrup is weak, it has a sweet taste, with a slight bitter-sour finish.

Preparation of aqueous extraction from viburnum fruits An analytical sample of the raw material is ground to a particle size passing through a sieve with a hole size of $1 \mathrm{~mm}$. About $2 \mathrm{~g}$ (accurately weighed) of the crushed raw material is placed in a $100 \mathrm{ml}$ flask, $40 \mathrm{ml}$ of purified water is added, mixed thoroughly and kept in a boiling water bath for 1 hour. The extract is cooled, filtered through a paper filter into a $100 \mathrm{ml}$ volumetric flask. The raw materials remaining in the flask and on the filter are washed with $20 \mathrm{ml}$ portions of purified water twice, transferred back to the flask and the extraction is repeated for 1 hour. Then the extract is cooled, filtered through a paper filter into a $100 \mathrm{ml}$ volumetric flask, the remaining raw materials in the flask and on the filter are washed by $10 \mathrm{ml}$ of purified water, the volume is adjusted to the mark with purified water and mixed.

Infusion preparation About $10 \mathrm{~g}$ ( 1 tablespoon) of the fruits is placed in an enamel dishware, $200 \mathrm{ml}$ ( 1 cup) of hot boiled water is poured, covered with a lid and heated in a boiling water bath for 15 minutes,

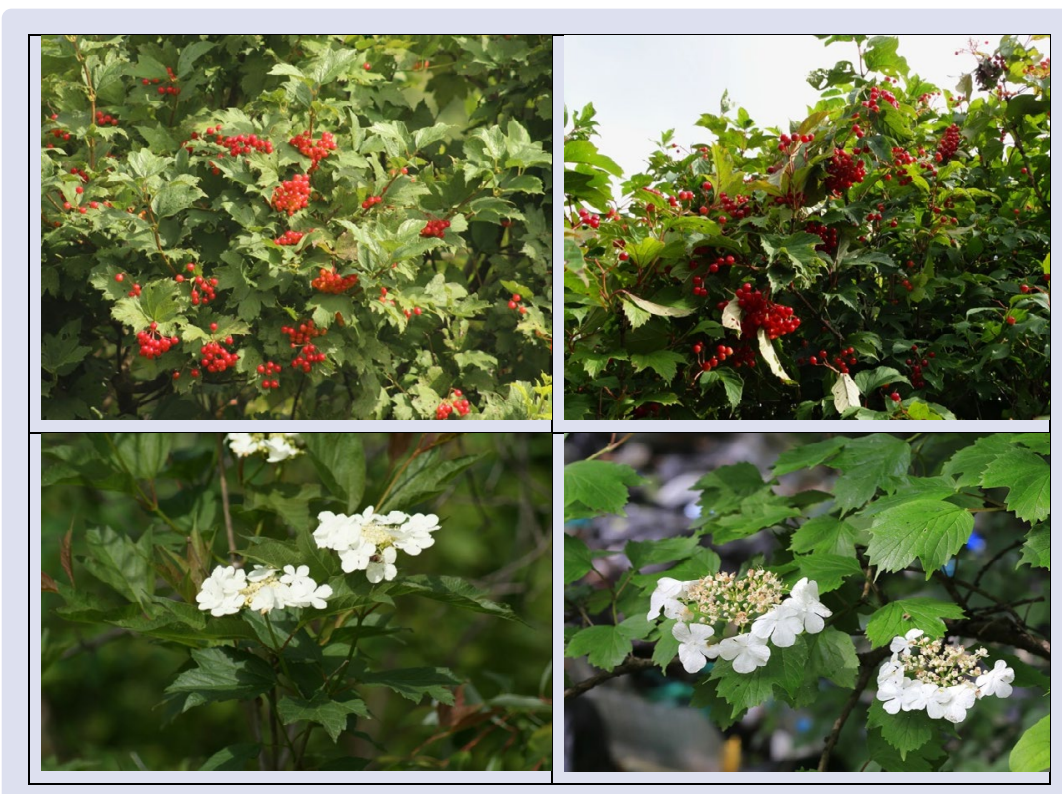

Figure 1: Guelder-rose (left,) Sargent's guelder-rose (right) in the flowering phase (bottom) and in the fruiting phase (top).

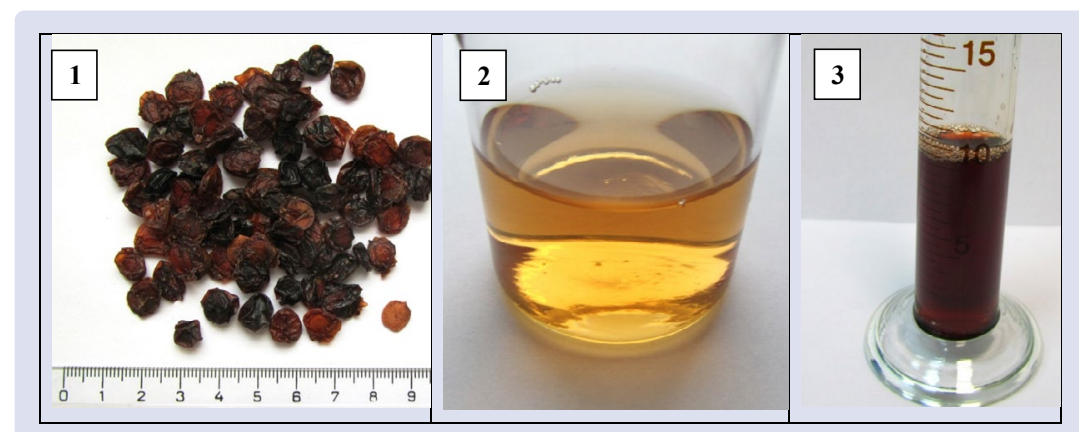

Figure 2: Medicinal herbal preparations of viburnum fruits: dried viburnum fruits (1), viburnum fruits infusion (2), viburnum syrup (3). 
cooled at room temperature for 45 minutes, filtered, the remaining raw materials are squeezed out. The volume of the resulting infusion is adjusted with boiled water to $200 \mathrm{ml}$. The resulting infusion is filtered through a paper filter.

Syrup sample preparation About $5 \mathrm{~g}$ (accurately weighed) of the syrup is placed in a $100 \mathrm{ml}$ flask, $70 \mathrm{ml}$ of purified water are added, mixed thoroughly, filtered through a paper filter into a $100 \mathrm{ml}$ volumetric flask. The flask and filter are washed twice with $10 \mathrm{ml}$ portions of purified water. The volume of the resulting infusion is adjusted to the mark with purified water and mixed.

The following instrumentation was used for HPLC analysis of monomeric sugars: Agilent 1260 Series HPLC system equipped with autosampler/injector, four-channel gradient pump, column thermostat, refractive index detector), software (ChemStation Version B.01), column (Waters Sugar-Pack I, $10 \mu \mathrm{m}, 300 \times 6.5 \mathrm{~mm}$ ).

Isocratic elution was performed using purified water (with the addition of Ca-EDTA $0.05 \mathrm{mg} / \mathrm{ml}$ ) as the mobile phase, at a flow rate of 0.5 $\mathrm{mL} / \mathrm{min}$. The column was maintained at $80^{\circ} \mathrm{C}$, the refractive index detector - at $35{ }^{\circ} \mathrm{C}$. The injection volume was $10 \mu \mathrm{L}$, analysis time $20 \mathrm{~min}$. Qualitative and quantitative determinations were based on the injection of an external standard solutions prepared as follows: $100 \mathrm{~mL}$ water containing $1.5 \mathrm{~g}$ of glucose, $1.5 \mathrm{~g}$ of fructose and $1.0 \mathrm{~g}$ of sucrose.

The standard samples of glucose D-(+) (CAS 50-99-7, $\geq 99.5 \%)$, L-(+)fructose (CAS 7776-48-9, $\geq 97.0 \%$ ), sucrose (CAS 57-50-1, $\geq 99.5 \%$ ) were purchased from Sigma-Aldrich (USA).

\section{RESULTS AND DISCUSSION}

The main free monomeric carbohydrates of viburnum fruits and preparations based on them are glucose, fructose, and sucrose (Figure 3). The composition of carbohydrates is an important characteristic along with the content of organic acids. The total content of simple sugars in the raw materials of viburnum is $28.393 \pm 0.528 \%$, in the infusion $-0.499 \pm 0.015 \%$, in the syrup $-69.736 \pm 1.551 \%$ (Table 1 ). The typical chromatograms are presented in Figure 3. The sugars' degree of passing into infusion is $74.34 \%$. The characteristic ratio of glucose: fructose: sucrose in dried viburnum fruits is 8.1:5.4:1, in infusion 7.0:5.7:1, and in syrup - 9.2:8.8:1 (Figure 4). This ratio can be used in the control of drugs based on viburnum fruits. According to the study, the ratio of glucose: fructose in samples of fresh viburnum fruits is 1.01.5 ; our findings for dried fruits fall within this range.

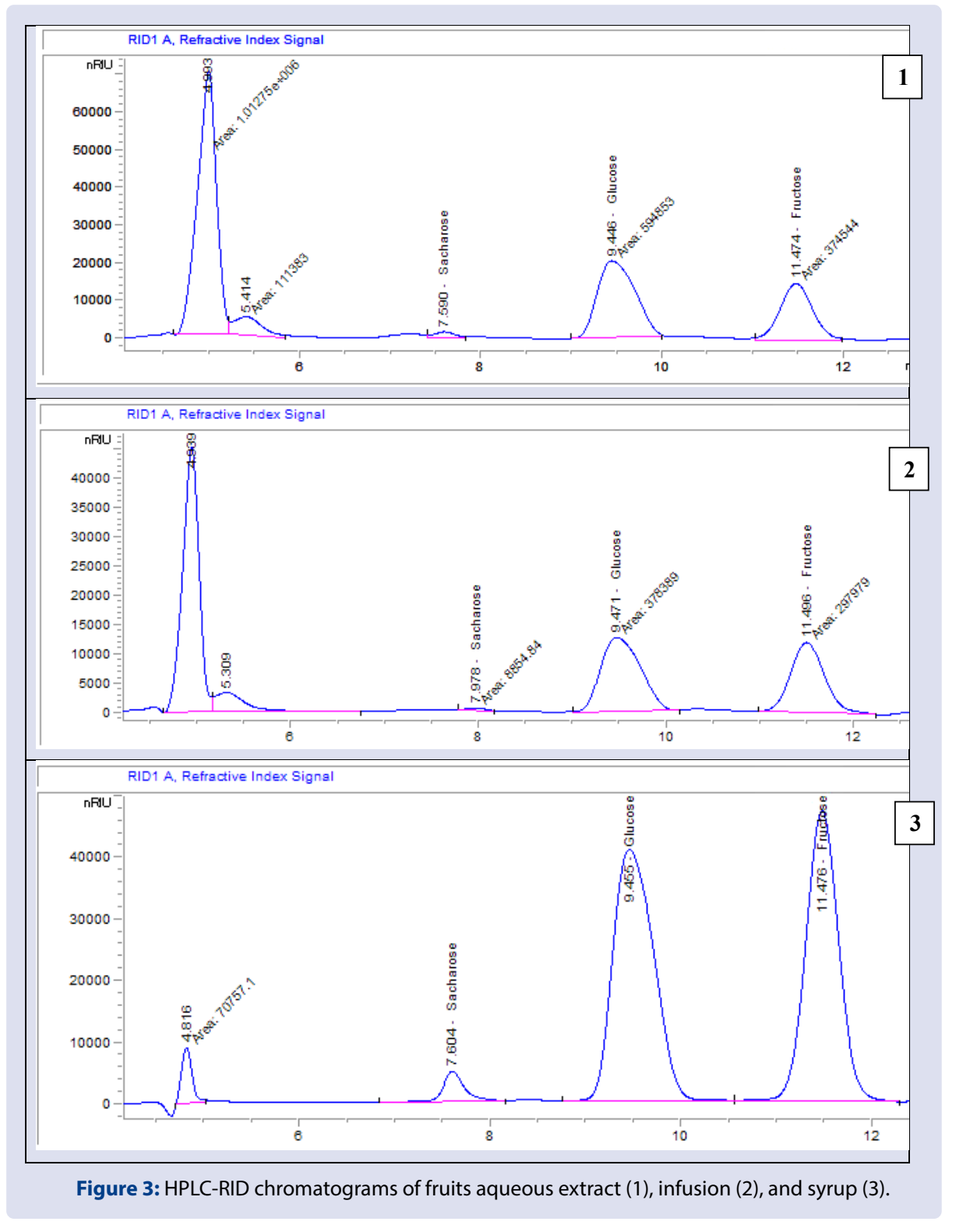


Table 1: The composition and content of monomeric sugars in viburnum fruits and drugs based on it.

\begin{tabular}{cccccc}
\hline \multirow{2}{*}{ Drug } & \multicolumn{4}{c}{ Sugar content, \% } \\
\cline { 2 - 6 } & glucose & fructose & sucrose & Total content & glucose: fructose: sucrose ratio \\
\hline dried viburnum fruits & $15,769 \pm 0,300$ & $10,667 \pm 0,192$ & $1,957 \pm 0,036$ & $28,393 \pm 0,528$ & $8,1: 5,4: 1$ \\
viburnum fruits infusion & $0,254 \pm 0,006$ & $0,208 \pm 0,007$ & $0,036 \pm 0,002$ & $0,499 \pm 0,015$ & $7,0: 5,7: 1$ \\
viburnum syrup & $33,726 \pm 0,708$ & $32,343 \pm 0,776$ & $3,667 \pm 0,067$ & $69,736 \pm 1,551$ & $9,2: 8,8: 1$ \\
\hline
\end{tabular}

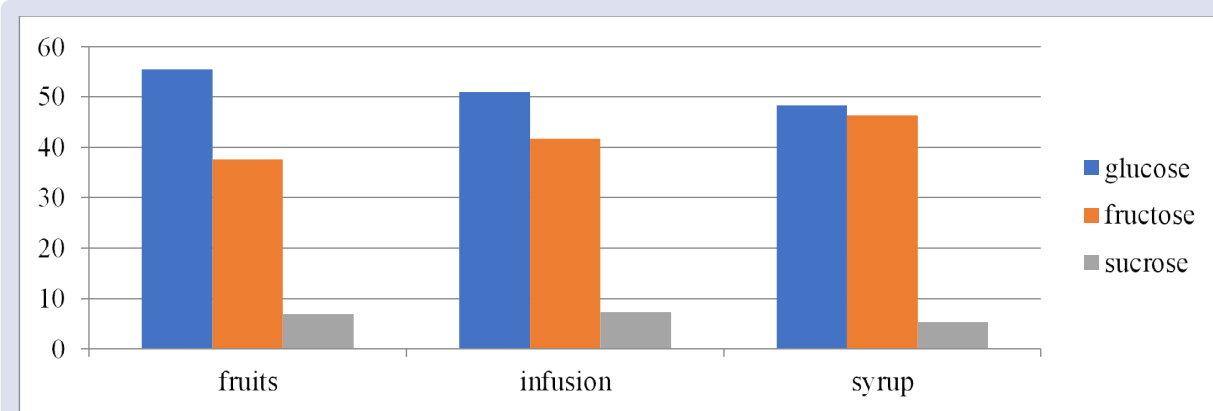

Figure 4: Monomeric sugar ratio in viburnum fruits and drugs based on it.

The profile and content of monomeric sugars, along with other BAS groups, can serve as indicators of identity and good quality when standardizing dried, fresh, freshly frozen viburnum fruits, drugs, extracts, and dietary supplements based on it.

\section{CONCLUSION}

As a result of the studies, the technique for determining the concentrations of sucrose, glucose, and fructose was tested in the analysis of the viburnum fruits and drugs based on it using the HPLC-RID method. The advantages of this technique are the lack of time-consuming sample preparation and, as a result, the rapidity of the technique. Using this technique, it is possible to monitor the carbohydrate composition at all stages of the pharmaceutical manufacturing process. Techniques based on the HPLC-RID method should be introduced into the routine pharmacopoeial analysis since it is very informative and makes it easy to identify poor-quality drugs.

\section{ACKNOWLEDGMENT}

The publication has been prepared with the support of the "Russian Academic Excellence Project 5-100", Ministry of Education and Science of the Russian Federation (the Agreement number 02.A03.21.0008).

\section{CONFLICTS OF INTEREST}

None.

\section{REFERENCES}

1. USSR State Pharmacopoeia, XI ed., Vol. 2. Moscow: Medicine 1989;400.

2. State Pharmacopoeia of Russian Federation, XIV ed., Vol. IV. Federal electronic medical library. The Russian Federation Ministry of Health [Official site]. URL: http://femb.ru/femb/pharmacopea.php Accessed date 05.08.2019 [in Russian].

3. Drug Guide RLS® https://www.rlsnet.ru/ Accessed date 05.08.2019 [in Russian].

4. State Register of Medicines. The Russian Federation Ministry of Health [Official site]. URL: http://grls.rosminzdrav.ru/grls.aspx Accessed date 05.08.2019 [in Russian].

5. Perova IB, Zhogova AA, Cherkashin AV, Éller KI, Ramenskaya GV, Samylina IA. Biologically active substances from european guelder berry fruits. Pharmaceutical Chemistry Journal. 2014;48(5):332-9.
6. Kraujalytė V, Venskutonis PR, Pukalskas A, Česonienė L, Daubaras R Antioxidant properties and polyphenolic compositions of fruits from different European cranberrybush (Viburnum opulus L.) genotypes. Food Chemistry. 2013;141(4):3695-702.

7. Česonienè $L$, Daubaras $R$, Viškelis $P$, Šarkinas A. Determination of the total phenolic and anthocyanin contents and antimicrobial activity of Viburnum opulus fruit juice. Plant Foods for Human Nutrition. 2012;67(3):256-61.

8. Sedat Velioglu Y, Ekici L, Poyrazoglu ES. Phenolic composition of European cranberrybush (Viburnum opulus L.) berries and astringency removal of its commercial juice. International Journal of Food Science \& Technology. 2006;41(9):1011-5.

9. Zhbanova EV, Maslennikov Al. The estimation of viburnum variety by qualitative features and biochemical contents of fruits. Bulletin of Michurinsk State Agrarian University. 2015;1:11-4 [in Russian].

10. Evtukhova OM, Teplyuk NYu, Leontiev VM, Ivanova GV. The content of biologically active compounds in the fruits of viburnum and honeysuckle, growing in the Krasnoyarsk Territory. Khimiya Rastitel'nogo Syr'ya. 2000;1:77-9 [in Russian].

11. Deineka VI, Chulkov AN, Deineka LA, Gandarmova PA, Sorokopudov VN Rybitskyi SM. HPLC determination of some viburnum fruits anthocyanins. Sorbtsionnye I Khromatograficheskie Protsessy 2014;14(3):434-42 [in Russian].

12. Moldovan B, David L, Chișbora C, Cimpoiu C. Degradation kinetics of anthocyanins from European cranberrybush (Viburnum opulus L.) fruit extracts. Effects of temperature, pH and storage solvent. Molecules. 2012;17(10):1165566.

13. Zayachkivska OS, Gzhegotsky M R, Terletska O I, Lutsyk D A, Yaschenko A M, Dzhura OR. Influence of Viburnum opulus proanthocyanidins on stress-induced gastrointestinal mucosal damage. Journal of Physiology and Pharmacology 2006;57:155.

14. Sergunova EV, Marakhova Al, Avrach AS. Methods for the quantification of organic acids in raw medicinal plant materials and aqueous extracts. Pharmacy 2013;4:8-11 [in Russian].

15. Sergunova EV, Zaitseva NA, Samylina IA. Impact of a preservation mode on the quality of the fruits and aqueous extracts of guelder rose (Viburnum opulus). Pharmacy. 2009;5:16-8 [in Russian].

16. Karimova AR, Yunusova SG, Galkin EG, Fedorov NI, Yunusov MS. Lipids and lipophilic components of Viburnum opulus fruits during maturation. Russian Chemical Bulletin. 2004;53(1):245-50 [in Russian].

17. Kraujalytè $V$, Leitner $E$, Venskutonis PR. Chemical and sensory characterisation of aroma of Viburnum opulus fruits by solid phase microextraction-gas chromatography-olfactometry. Food Chemistry. 2012;132(2):717-23.

18. Andreeva VY, Isaykina NV, Tsybukova TN, Petrova EV. The study of the elemental composition of fruits of Viburnum opulus $\mathrm{L}$. and Sorbus aucuparia $\mathrm{L}$. various modern methods. Khimiya Rastitel'nogo Syr'ya. 2016;1:177-80 [in Russian].

19. Stepanov SV, Savvina AL. Derivation and standardization of Sargenta arrowwood fruit syrup. Pacific Medical Journal. 2010;2(40):102-4 [In Russian]. 


\section{GRAPHICAL ABSTRACT}
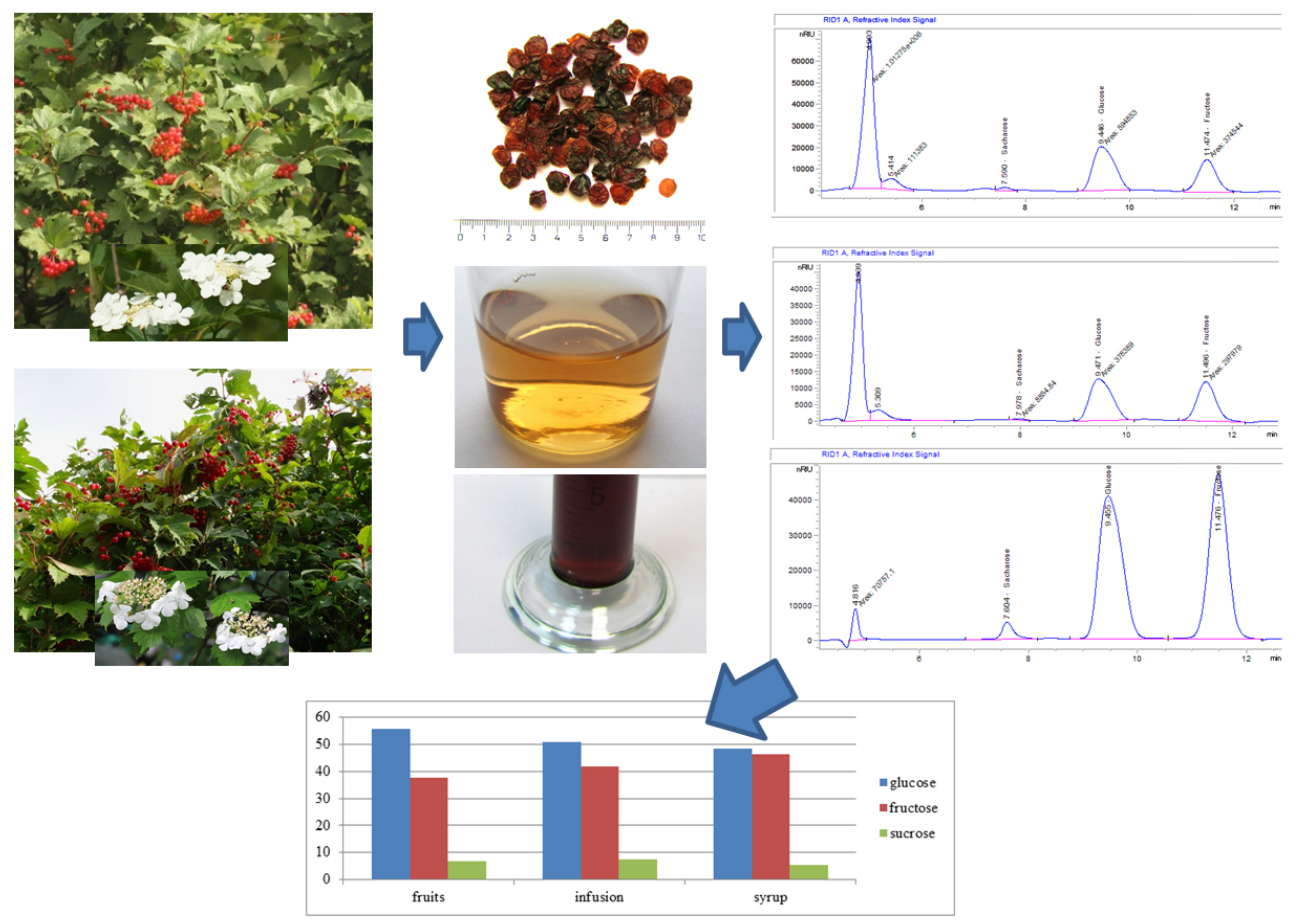

\section{ABOUT AUTHORS}

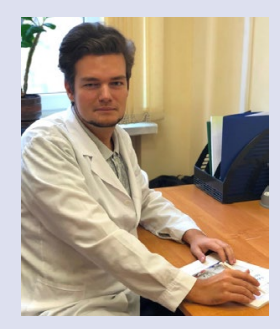

Bokov Dmitry Olegovich: is candidate of Pharmaceutical Sciences (Ph.D.), Associate Professor, Department of Pharmaceutical Natural Sciences, Department of Analytical, Physical and Colloid Chemistry, Institute of Pharmacy, Sechenov University; Laboratory of Food Chemistry, Federal Research Center for Nutrition, Biotechnology and Food Safety. Research Interests: are pharmacognosy, analytical chemistry, investigation of the composition and content of biologically active compounds in crude herbal drugs using modern instrumental methods of analysis (HPLC with RID, UV, MS-MS detection, GC-MS).

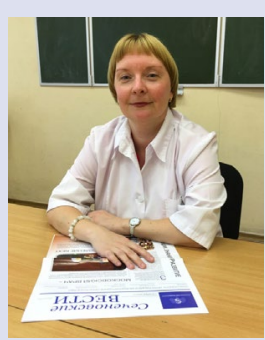

Sergunova Ekaterina Vyacheslavovna: is doctor of Pharmaceutical Sciences, Associate Professor, Professor of Department of Pharmaceutical Natural Sciences, Institute of Pharmacy, Sechenov University. Research Interests: are pharmacognosy, influence of conservation methods on the composition and content of biologically active substances in medicinal plant materials.

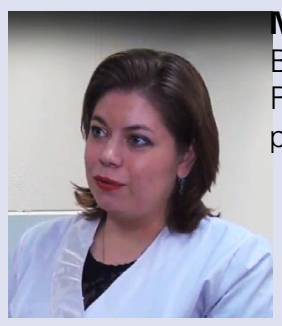

Marakhova Anna Igorevna: is doctor of Pharmaceutical Sciences, Professor, head of Institute of Biochemical Technology and Nanotechnology, Peoples' friendship university of Russia (RUDN University). Research Interests: are pharmacognosy, unification of physico-chemical methods of analysis of medicinal plant materials and herbal preparations, development and standardization of herbal medicines. 


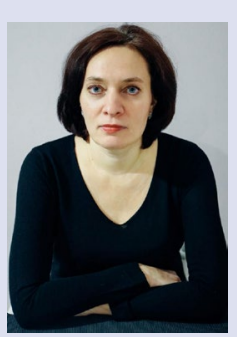

Morokhina Svetlana Lvovna: is candidate of Pharmaceutical Sciences (Ph.D.), Preparatory faculty, Financial University under the Government of the Russian Federation (Financial University). Research Interests: are pharmacognosy, standardization of crude herbal drugs and herbal preparations.

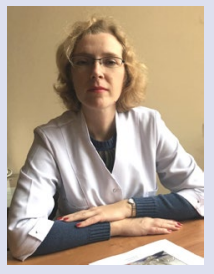

Plakhotnaia Olga Nikolaevna: is candidate of Chemical Sciences (Ph.D.), Associate Professor, Department of Analytical, Physical and Colloid Chemistry, Institute of Pharmacy, Sechenov University. Research Interests: study and modeling of the mechanism of metal oxides dissolution in acidic and ammonia media in the presence of complexones.

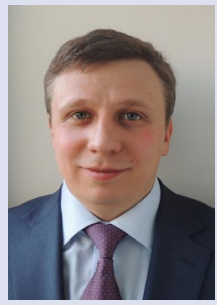

Krasnyuk Ivan Ivanovich (junior): is doctor of Pharmaceutical Sciences, Professor, Head of Department of Analytical, Physical and Colloid Chemistry, Institute of Pharmacy, Sechenov University. Research Interests: bioavailability increasing of dosage forms using solid dispersions.

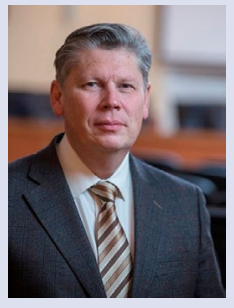

Bessonov Vladimir Vladimirovich: is doctor of Biological Sciences, Head of Laboratory of Food Chemistry, Federal Research Center for Nutrition, Biotechnology and Food Safety. Research Interests: study of technological contaminants and secondary oxidation products content in highly processed dietary fats; development of a methodological and regulatory framework to ensure modern requirements for the quality of food products and the development of technologies for evaluating the effectiveness of specialized food products.

Cite this article: Bokov DO, Sergunova EV, Marakhova Al, Morokhina SL, Plakhotnaia ON, Krasnyuk II, et al. Determination of Sugar Profile in Viburnum Fruits and its Dosage Forms by HPLC-RID. Pharmacog J. 2020;12(1):103-8. 